Christoph Wolff (Cambridge/Massachusetts)

\title{
Zum Gedenken an Wolfgang Rehm (1929-2017)
}

Er galt im Fach Musikwissenschaft als eine Schlüsselfigur und war ein überaus fachkundiger, ideenreicher, einsatzbereiter und unbestechlicher Mittelsmann und Organisator. Er war mit fast allen Bereichen des Musiklebens eng vertraut, und seine Schaltstelle lag für lange Zeit im Bärenreiter-Verlag Kassel im Herzen der Bundesrepublik, ehemals zugleich in Grenznähe zur DDR. So machten die von ihm betreuten Musiker-Gesamtausgaben ihn über editorische und verlegerische Kontakte hinaus zum wichtigen Verbindungs- und Vertrauensmann zwischen West und Ost. Aber auch in Europa und Übersee wirkte er grenzüberwindend, nicht zuletzt durch seine führenden Funktionen bei der International Association of Music Libraries (IAML) und dem Répertoire International des Sources Musicales (RISM), bei den Trägervereinen der Gesamtausgaben, der Neuen Bachgesellschaft, dem Mozarteum und manch anderen musikbezogenen Institutionen. Alle kannten ihn, doch er kannte nicht nur alle beim Namen, sondern wusste um die Fähigkeiten und Bedürfnisse eines jeden und mühte sich in besonderer Weise um die Förderung junger Musikwissenschaftler.

Ein für die Fachgeschichte wesentliches und bleibendes Verdienst Rehms bestand darin, dass er gemeinsam mit seinem ehemaligen Freiburger Kommilitonen Hanspeter Bennwitz für einen Großteil der musikwissenschaftlichen Editionsprojekte eine dauerhafte Finanzierung zu sichern wusste, zunächst übergangsweise bei der Stiftung Volkswagenwerk, sodann seit 1977 bei der Konferenz der deutschen Akademien der Wissenschaften (heute Union der Deutschen Akademien der Wissenschaften) in Mainz.

Man würde freilich Wolfgang Rehm nicht gerecht, wenn man in ihm nicht zuvörderst den weitblickenden und sorgfältigen, ja penibel genauen Wissenschaftler sehen würde. Am 3. September 1929 in München geboren, Sohn des bedeutenden Literaturwissenschaftlers Walther Rehm (Griechentum und Goethezeit), hatte er in Freiburg Musikwissenschaft, Germanistik und mittelalterliche Geschichte studiert und bei Wilibald Gurlitt 1952 mit einer Arbeit über die Chansons von Gilles Binchois promoviert. Unmittelbar danach begann sein Einstieg in das Musikverlagswesen, zuerst bei Breitkopf \& Härtel, sodann ab 1954 beim Bärenreiter-Verlag als wissenschaftlicher Mitarbeiter, Lektor, Cheflektor und schließlich 1975 Mitglied der Geschäftsleitung. Über ein Vierteljahrhundert hat er maßgeblich das wissenschaftliche Profil des Verlages mitgeprägt, schied jedoch 1982 aus und zog nach Salzburg, um sich hauptamtlich der Editionsleitung der Neuen Mozart-Ausgabe zu widmen. An der NMA war er seit 1960 beteiligt, ja eigentlich ihr Architekt. Da ihm die Mozart-Forschung seit eh und je am Herzen lag, wollte er den Rest seines Berufslebens wesentlich der Musik Mozarts widmen. So prägte er für viele Jahre die Programme der Salzburger Mozartwoche, organisierte den Internationalen Mozart-Kongress Salzburg 1991 und führte mit großer Umsicht die NMA 2007 zu ihrem Abschluss.

Viele Ehrungen wurden ihm zuteil. Dazu zählten 1977 das Österreichische Ehrenkreuz für Wissenschaft und Kunst, 1991 die Verleihung des Professoren-Titels durch das Land Baden-Württemberg und 2007 die Goldene Mozart-Medaille der Internationalen Stiftung Mozarteum sowie zahlreiche Ehrenmitgliedschaften. Seine beiden letzten Jahre waren von Krankheit getrübt, vor allem aber durch den Tod seiner geliebten Frau Helga. Am 6. April 2017 starb Wolfgang Rehm in Groß-Gerau bei Darmstadt. 